\title{
An electrochemical active valve
}

\author{
C. R. Neagu, ${ }^{a *}$ J. G. E. Gardeniers, ${ }^{a}$ M. Elwenspoek ${ }^{a}$ and J. J. Kelly ${ }^{b}$

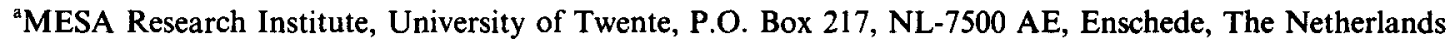 \\ bebye Institute, Utrecht University, P.O. Box 80.000, NL-3508 TA, Utrecht, The Netherlands
}

(Received 28 August 1996; in revised form 4 February 1997)

\begin{abstract}
A novel electrochemical microactuator was developed, which operates as an active valve. The microactuator consists of an electrochemical cell and a membrane that deflects because of the pressure of oxygen gas generated by electrolysis. Relatively large pressures (up to tens of bars) can be reached with only low energy consumption (in the $\mu \mathrm{W}$ range). In a first prototype a $\mathrm{Cu} / \mathrm{aq} .1 \mathrm{M} \mathrm{CuSO}_{4} / \mathrm{Pt}$ system was used in an electrochemical cell with dimensions $2 \times 2 \times 1 \mathrm{~mm}^{3}$, fabricated with silicon micromachining and thin film deposition techniques. When the actuator was driven at $1.6 \mathrm{~V}$ and currents below $50 \mu \mathrm{A}$, pressures of 2 bar could be obtained within seconds, causing membrane deflections in the 30 to $70 \mu \mathrm{m}$ range. It was found that, in order to improve the performance of the microactuator, it will be necessary to replace the $\mathrm{Cu} / \mathrm{Cu}^{2}+$ electrode. A possible alternative is the $\mathrm{Sb} / \mathrm{Sb}$-oxide electrode. This system was studied by cyclic voltammetry and the first results are promising. (C) 1997 Published by Elsevier Science Ltd
\end{abstract}

Key words: Silicon micromachining, microsystems, microactuator, microvalve, thin films, electrolysis, antimony oxide.

\section{INTRODUCTION}

Micro System Technology is a broad area with many applications in eg biomedicine, chemical analysis and liquid handling [1]. For microfluidics, basic components like pumps and valves, activated by different principles [2], have already been realized with the use of silicon microtechnology (Table 1; for an extensive comparison of active valves see $[3,4])$.

Depending on the application, some actuation principles may be preferable, but most of these need either high voltages (eg, electrostatic, piezoelectric) or have quite high power consumption with low efficiency (eg, heat dissipation in the case of thermal actuation), which limits their applicability. The goal of this research is to develop a micromachined active valve that provides a continuous regulation around a desired pressure value. To obtain a low energy consumption and to have the possibility of discontinuous supply of power, we opted for electrochemical actuation, which is based on the electrolysis of an aqueous electrolyte solution

*Author to whom correspondence should be address.
[5 8]. The basic idea is that reversible electrochemical reactions, which are driven by an external current source, lead to gas evolution or gas reduction (depending on the direction of the current); in a closed system the corresponding pressure rise or drop is used to change the deflection of a flexible membrane, which in turn can be used as a valve. If such an electrolytic cell is operated under open-circuit conditions, the pressure ideally will be constant so that no energy is required to maintain the deflection state of the valve.

Although under open circuit conditions the gas pressure built up in a previous electrolysis step should, in principle, remain constant, in practice this ideal situation is very difficult to achieve; the gas produced at one electrode (eg Pt [7]) may react at the other electrode (eg $\mathrm{Cu}$ [7]). One way to prevent this is to protect the second electrode with a semi-permeable membrane like Nafion ${ }^{\circledR}[9]$; this approach was followed in our earlier work [7, 8] and will be elaborated in this paper. Another approach would be to use a metal electrode passivated by eg a coherent oxide layer, which does not react with oxygen gas. In this study we shall consider the antimony-antimony oxide system for this purpose. 
Table 1.

Different types of micro-valves fabricated with silicon micromachining techniques

\begin{tabular}{lcccc}
\hline Actuation principle $[3,4]$ & Pressure $\left(10^{5} \mathrm{~Pa}\right)$ & Stroke $(\mu \mathrm{m})$ & Voltage $(\mathrm{V})$ & $\begin{array}{c}\text { Power consumption } \\
(\mathrm{mW})\end{array}$ \\
\hline Electrostatic & $<0.5$ & $<10$ & $100-200$ & $<1$ \\
Thermopneumatic & $1<P<100$ & $30<d<100$ & $5-20$ & $2000-5000$ \\
Electromagnetic & $<0.5$ & $>100$ & $20-50$ & $50-300$ \\
Piezoelectric & $<1$ & $10<d<50$ & $100-200$ & $<5$ \\
\hline
\end{tabular}

\section{ELECTROCHEMICAL REACTIONS AND ACTUATION PRINCIPLE}

The two electrochemical systems investigated in this study can be described as follows:

System $A: \mathrm{Cu} / \mathrm{aq} .1 \mathrm{M} \mathrm{CuSO}_{4} / \mathrm{Pt}$

The following reactions occur:

at Pt:

$$
2 \mathrm{H}_{2} \mathrm{O} \Leftrightarrow \mathrm{O}_{2}+4 \mathrm{H}^{+}+4 e^{-},
$$

at $\mathrm{Cu}$ :

$$
2 \mathrm{Cu}^{2+}+2 e^{-} \Leftrightarrow \mathrm{Cu} .
$$

For this system the working principle of the electrochemical actuator is as follows:

During pressure build-up, required for the deflection of a flexible valve membrane, the Pt electrode acts as an anode at which oxygen gas evolves; $\mathrm{Cu}$ is deposited at a copper cathode. During the pressure reduction stage, in which the membrane deflection is decreased, the polarity of the cell is reversed so that $\mathrm{O}_{2}$ is reduced at the $\mathrm{Pt}$ electrode and the $\mathrm{Cu}$ electrode dissolves. Ideally under open circuit conditions the oxygen pressure created previously should be maintained.

In earlier work [7] the main problem with the foregoing concept was found to be the reduction of oxygen gas at the $\mathrm{Cu}$ electrode during the pressure build-up stage and at open circuit. To reduce this effect, the copper electrode was covered with a thin layer of the ion-exchange polymer Nafion ${ }^{\mathrm{R}}$ : [9]. This polymer is permeable to polar compounds and positive ions, so that the current loop during electrolysis is closed, while negative ions and non-polar compounds like oxygen diffuse only slowly through it.

System B: $\mathrm{Sb}, \mathrm{Sb}_{x} \mathrm{O}_{y} /$ aq. $0.1 \mathrm{M} \mathrm{Na}_{2} \mathrm{SO}_{4} / \mathrm{Pt}$

It should also be possible to use a reversible metal/metal oxide electrode instead of the $\mathrm{Cu} /$ $\mathrm{Cu}^{2+}$ couple. In the case of the $\mathrm{Sb} / \mathrm{Sb}_{2} \mathrm{O}_{3}$ system, the reaction corresponding to equation (2) is:

At Sb:

$$
\mathrm{Sb}_{2} \mathrm{O}_{3}+6 \mathrm{H}^{+}+6 e^{-} \Leftrightarrow 2 \mathrm{Sb}+3 \mathrm{H}_{2} \mathrm{O} \text {. }
$$

In the case of the oxygen created at the Pt electrode during pressure build-up, it will not be reduced at the $\mathrm{Sb}$ electrode if it remains passivated, ie if the oxide layer is not completely removed during reac- tion (3). Furthermore, the oxide should be chemically stable in the solutions used in the actuator, and have a relatively low electrical resistance in order to limit the voltages required to operate the actuator.

\section{EXPERIMENTAL}

The microactuator with dimensions $2 \times 2 \times 1 \mathrm{~mm}^{3}$, fabricated from two silicon wafers with micromachining and thin film techniques, consists of two main parts, viz. an electrochemical cell and a membrane, which is used for pressure-todeflection transformation (Fig. 1(a)). One wafer contains a cavity for the electrolyte solution ( $c a$. $1.2 \mathrm{~mm}^{3}$ ), and a $1 \times 1 \mathrm{~mm}^{2}$ silicon nitride or polyimide membrane. Polyimide has a lower Young's modulus which means that less pressure is necessary to obtain the same deflection as with as a silicon nitride membrane. The $1 \mu \mathrm{m}$ thick silicon nitride membranes, fabricated with Low Pressure Chemical Vapour Deposition (to give low residual stress) and silicon micromachining, are either flat or corrugated; the details of the fabrication process can be found in [7]. The polyimide membranes are fabricated as follows: a silicon wafer with a $1 \mu \mathrm{m}$ silicon nitride layer is etched from the back in $\mathrm{KOH}$ solution; on the front a polyimide layer is deposited by spin coating and subsequently cured; to improve the adhesion of this layer, a $20 \mathrm{~nm} \mathrm{Cr}$ film is first deposited by magnetron sputtering. Finally the silicon nitride layer is removed by Reactive Ion Etching (RIE) in an $\mathrm{O}_{2} / \mathrm{CHF}_{3}$ plasma, while the $\mathrm{Cr}$ layer is removed by wet etching. On another wafer the two electrodes, $\mathrm{Pt}$ and $\mathrm{Cu}$, are deposited by magnetron sputtering and patterned by a lift-off technique. The effective area of the $\mathrm{Cu}$ electrode is ca. $0.2 \mathrm{~mm}^{2}$ and that of the $\mathrm{Pt}$ electrode is $c a$. $1.36 \mathrm{~mm}^{2}$.

In order to improve the adhesion of the Nafion film on the $\mathrm{Cu}$ electrode and to allow thicker Nafion films with a small area to reduce oxygen diffusion to the $\mathrm{Cu}$, a polyimide mesh was used (Fig. 1(b)). Tests have shown that the mechanical stability of this polymer membrane is sufficient for our application. The $10 \mu \mathrm{m}$ thick polyimide mesh uses a $1.5 \mu \mathrm{m}$ thick aluminum sacrificial layer, that is etched selectively after the polyimide is cured. 
(a)
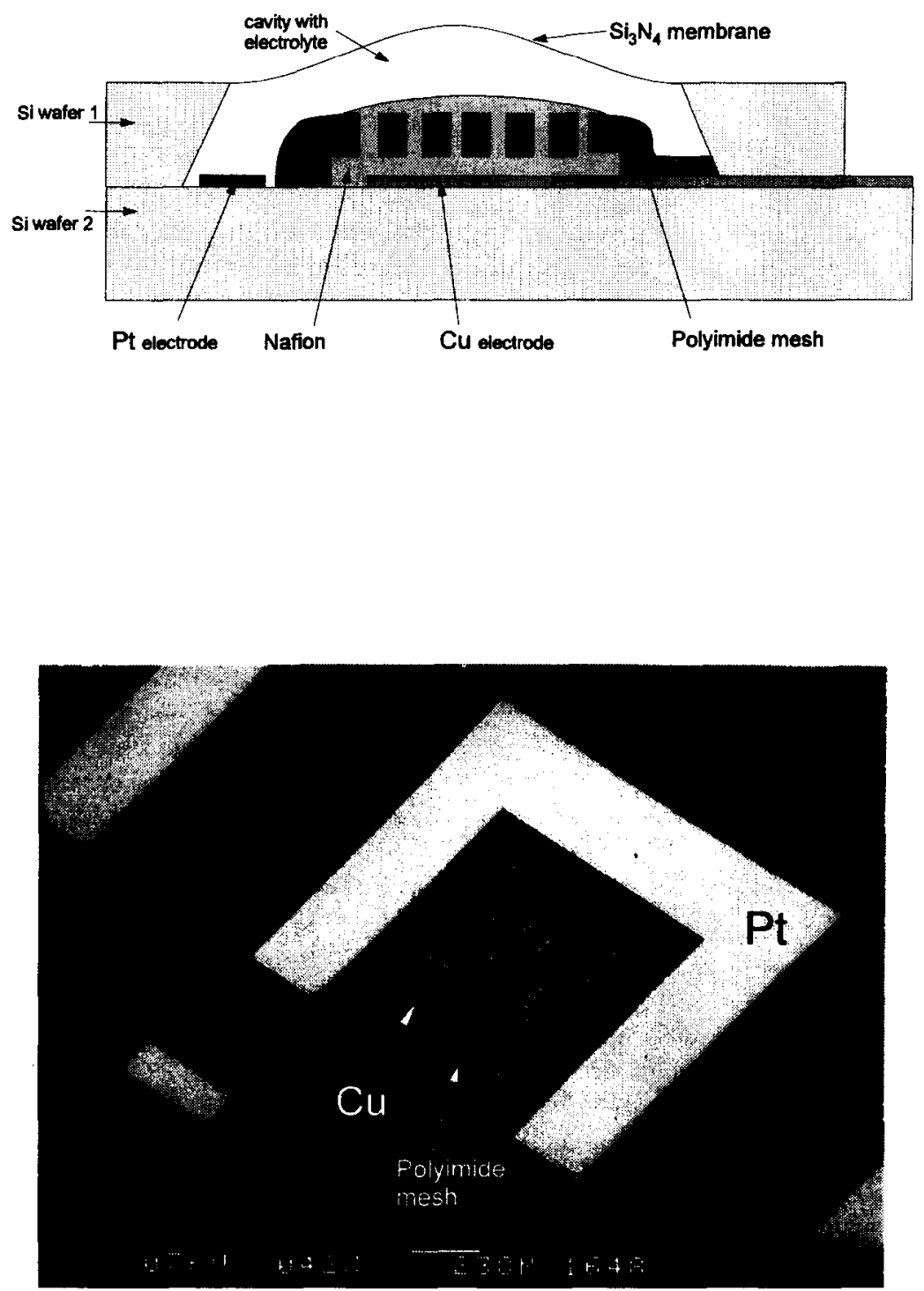

(b)

Fig. 1. (a) Schematic cross-section of the electrochemical microactuator. (b) SEM photo of the Pt and Cu electrodes, and the polyimide mesh (top view).

The polyimide used is photosensitive Probimide ITR3-200 (OCG Microelectronic Materials NV), which can easily be patterned by photolithography.

Pressure-deflection measurements [8], performed with a stylus profilometer, showed that for a pressure of 2 bar a $1 \mu \mathrm{m}$ thick corrugated silicon nitride membrane deflects about $30 \mu \mathrm{m}$, while an $8 \mu \mathrm{m}$ thick flat polyimide membrane has a deflection of $70 \mu \mathrm{m}$.

The electrochemical cell cavity was sealed at room temperature with epoxy glue, which was tested for gas leaks. The electrolyte is an aqueous solution of $1 \mathrm{M} \mathrm{CuSO}$. The cavity is filled by immersing the two wafers into the electrolyte in a glass beaker, and placing it in a vacuum chamber.
In this way the chamber is completely filled without any gas bubbles.

To evaluate electrochemical system B, we performed cyclic voltammetric measurements on $\mathrm{Sb}$ electrodes in aqueous solution. These electrodes were made from $99.99 \% \mathrm{Sb}$ rods supplied by Highways International. The electrodes had a surface area of about $7 \mathrm{~mm}^{2}$ in contact with the test solution. Before the measurements, the surface was polished mechanically. Measurements were performed in $0.1 \mathrm{M} \mathrm{Na}_{2} \mathrm{SO}_{4}$ at room temperature without stirring. A Pt plate served as counter electrode and $\mathrm{Ag} / \mathrm{AgCl}$ as reference electrode $(0.222 \mathrm{~V}$ vs SHE). All experiments were done at a scan rate of $25 \mathrm{mV} /$ s, using an EG\&G 366A potentiostat. 


\section{RESULTS AND DISCUSSION}

As described above, a small actuator was fabricated on the basis of electrochemical system A. To characterize this actuator, the pressure-deflection characteristics of membranes were first measured with air pressure [7]. From this calibration curve, the estimated volume of the cavity and measurements of the deflection during electrolysis, the amount of oxygen gas produced during electrolysis could be calculated. In the following experiments, only flat silicon nitride membranes were used.

A cyclic voltammogram of an open microactuator (without a silicon nitride membrane) using electrochemical system $A$, is shown in Fig. 2, for the potential range of $-0.2 \mathrm{~V}$ to $+1 \mathrm{~V}$. The potential was measured between the $\mathbf{P t}$ electrode and a $\mathbf{P t}$ wire, which served a "pseudo" reference electrode; a $\mathrm{Cu}$ electrode was used as counter electrode. The electrolyte was an aqueous solution of $1 \mathrm{M}$ $\mathrm{CuSO}_{4} \cdot 5 \mathrm{H}_{2} \mathrm{O}$. Both reactions (1) and (2) are clearly observed in Fig. 2; the cathodic and anodic peaks at $c a .-0.15 \mathrm{~V}$ are related to copper deposition and dissolution at the Pt surface. Oxygen gas is formed at potentials higher than $1.2 \mathrm{~V}$.

Electrochemical experiments on a working actuator can be performed either by controlling the current externally and measuring the resulting changes in potential, or by controlling the potential and measuring the resulting current. The measurements described below were conducted at constant current. In this way, the amount of gas formed could be determined and compared with that calculated from the deflection of the membrane. In the experiments the current is stepped from zero to a finite value, which is kept constant during the experiment, while the potential of the cell is measured as a function of time.

The dynamic behavior of the microactuator was investigated by measuring the membrane deflection optically, with a Laser Nano Sensor LNS (Sensors 95 B.V.), based on an autofocusing principle. For an applied current of $10 \mu \mathrm{A}$, the voltage across the actuator cell increased asymptotically to a value of 1.6-1.7 V, while the deflection of the silicon nitride membrane increased to $13 \mu \mathrm{m}$ within $9 \mathrm{~min}$. When the current was increased to $50 \mu \mathrm{A}$, the reactions showed the same general behavior, only faster. A deflection of $11.5 \mu \mathrm{m}$ was obtained in $1 \mathrm{~min}$., as is shown in curve AB of Fig. 3 ( $\square$ dots). This figure also shows the decrease in membrane deflection that occurs when the cell is short-circuited at point $\mathrm{B}$; the pressure decreases to $1 \mathrm{bar}$ in about $15 \mathrm{~min}$. A similar measurement for open circuit is also shown by $\diamond$ dots in Fig. 3; in point B the electrodes are disconnected (open circuit). The decay time (defined as the time in which the deflection decreases by a factor of $e$ ) is $\tau=93 \mathrm{~min}$.

In the above experiments the build-up time is mainly determined by the charge passed through the cell, while the decrease of pressure in the shortcircuited state depends on the rates of the electrochemical reactions and on the electrical impedance of the cell. The rate of decrease in pressure under open circuit conditions depends on the rate at which the oxygen diffuses through the Nafion ${ }^{(\mathbb{B}}$ layer and is reduced at the $\mathrm{Cu}$ and metal corrodes:

$$
2 \mathrm{Cu}+\mathrm{O}_{2}+4 \mathrm{H}^{+} \Leftrightarrow 2 \mathrm{Cu}^{2+}+2 \mathrm{H}_{2} \mathrm{O} .
$$

When the $\mathrm{Cu}$ and $\mathrm{Pt}$ electrodes are short-circuited, oxygen can also be reduced at the noble metal and the rate of $\mathrm{Cu}$ corrosion is enhanced; as expected, the pressure drops faster in this case, as can be seen in Fig. 3. With the use of the polyimide mesh the area of Nafion ${ }^{\circledR}$ is decreased, while its thickness is increased, leading to an increase of the decay time in open circuit conditions from $6 \mathrm{~min}$ in our first prototype [7] to $93 \mathrm{~min}$ in the present case.

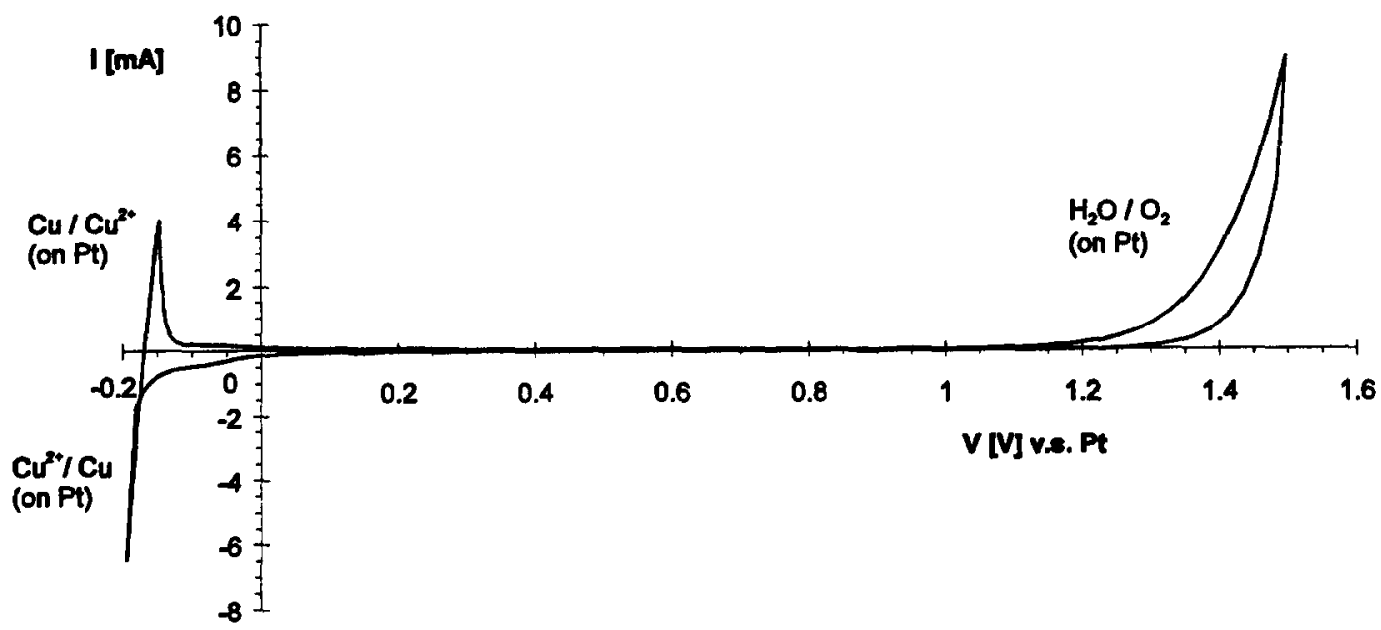

Fig. 2. Cyclic voltammogram of the open electrochemical cell (without a silicon nitride membrane) with a Pt working electrode, a Cu counter electrode, and a $\mathrm{Pt}$ wire as "pseudo" reference electrode, in $1 \mathrm{M} \mathrm{CuSO}_{4}$, scan rate $25 \mathrm{mV} / \mathrm{s}$. 


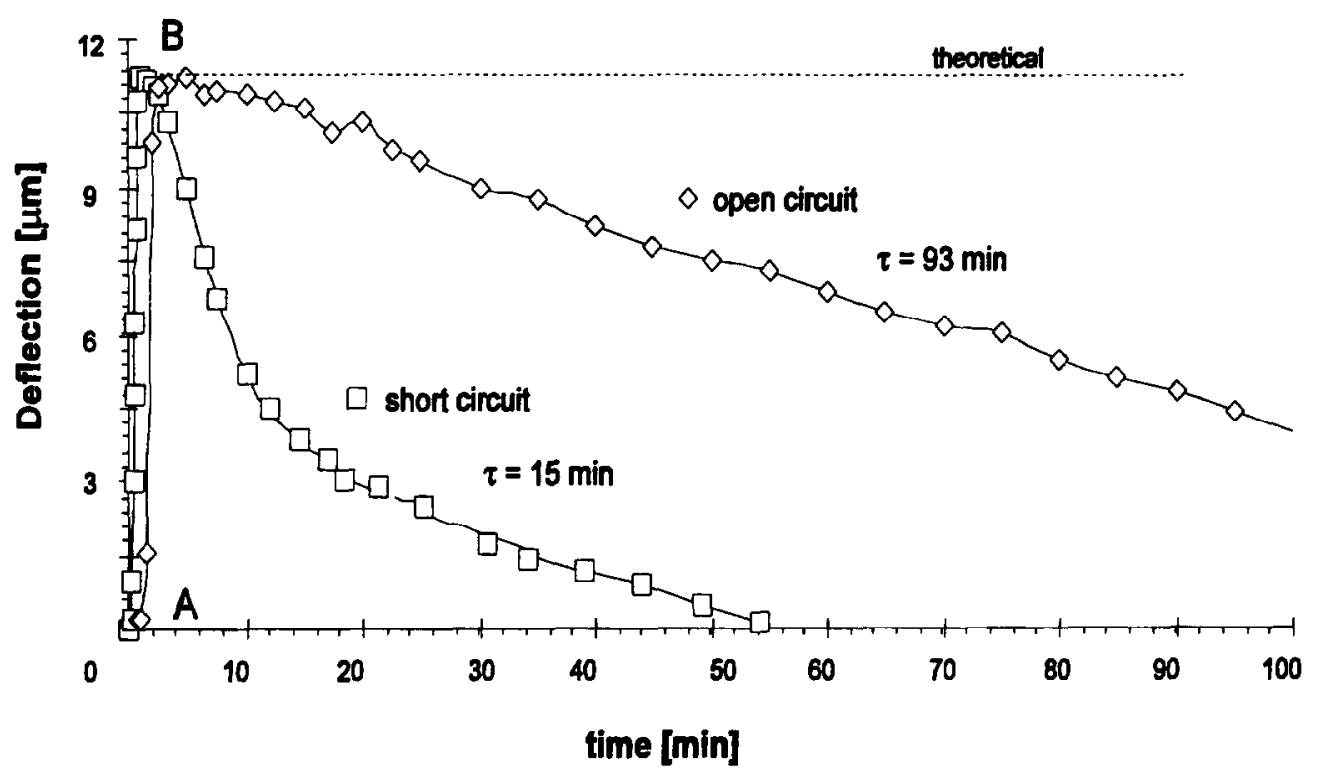

Fig. 3. The variation in time of the membrane deflection for a current of $50 \mu \mathrm{A}$. Curve $\mathrm{AB}$ is the deflection of the membrane due to $\mathrm{O}_{2}$ gas generation. The decrease in pressure is due to oxygen reduction at the $\mathrm{Cu}$ electrode (open circuit case) and at both $\mathrm{Cu}$ and Pt electrodes (short circuit case).

In order to study the feasibility of electrochemical system B, we performed a number of cyclic voltammetry experiments on $\mathrm{Sb}$ electrodes in aqueous solutions. Figure 4 shows three consecutive voltammograms. In the first scan, from 0 to $2 \mathrm{~V}$, the anodic current is almost independent of the applied potential until the scan direction is reversed. In the second sweep, from 0 to $5 \mathrm{~V}$, the current remains low until the limit of the first scan $(2 \mathrm{~V})$ is passed. At this point the current rises to a value close to the limiting value of the first scan. In the third sweep, the limit of the second scan $(5 \mathrm{~V})$ has to be passed before the current again reaches its potential independent value. When the scan direction is reversed, the current drops in all cases. The fact that in the second and third runs the potential limit of the previous run has to be exceeded before the limiting current is observed, points to the growth of an oxide (the reverse of reaction (3)), whose thickness is dependent on potential. This, and the con- stant current in the forward scan direction at constant scan rate indicate field-dependent growth of the oxide. If the potential is kept constant or the scan direction is reversed, the current (and the oxide growth rate) drops. Antimony oxide clearly remains on the surface when the potential is kept constant or when the voltage is scanned back to 0 V.

In the third experiment of Fig. 4, the metal is anodized to $10 \mathrm{~V}$. Considerably higher potentials (up to $50 \mathrm{~V}$ ) can be used to give a thicker oxide. However, the quality of antimony oxides obtained in this way is, in general, rather poor: extremely rough and porous surfaces may result $[10,11]$. For the present application antimony oxides formed by other methods may be more practical; experiments to evaluate this are currently being performed.

Figure 5 shows results relating to the cathodic reduction of the oxide film. An Sb electrode was anodized for $1 \mathrm{~h}$ at $+5 \mathrm{~V}$ and the potential was

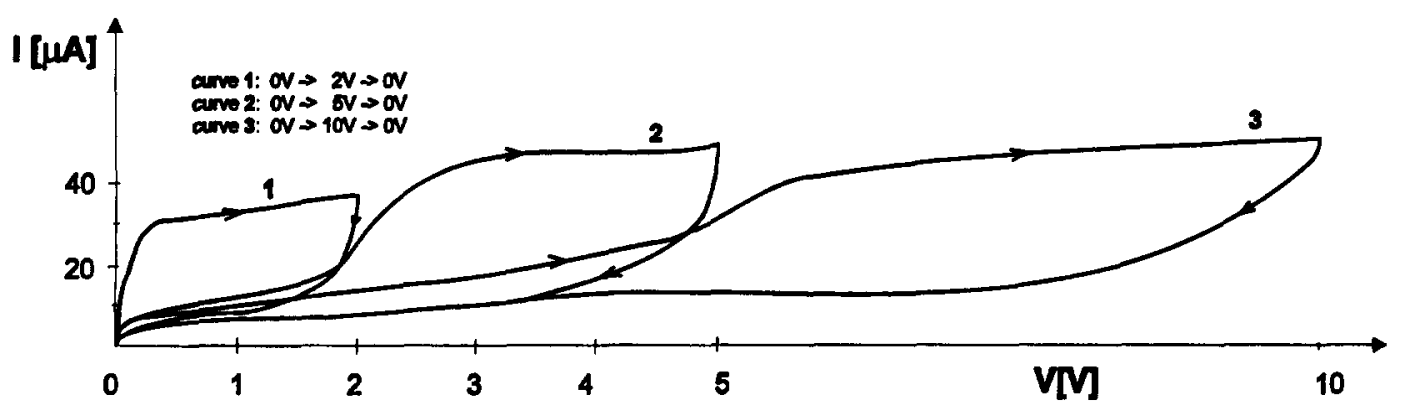

Fig. 4. Cyclic voltammogram of an $\mathrm{Sb}$ electrode in the oxide formation range; curves are shown for successive scans starting from $0 \mathrm{~V}$ to increasing anodic potentials. $0.1 \mathrm{M} \mathrm{Na}_{2} \mathrm{SO}_{4}, \mathrm{Pt}$ counter electrode, $\mathrm{Ag} / \mathrm{AgCl}$ reference electrode, scan rate $25 \mathrm{mV} / \mathrm{s}$. 


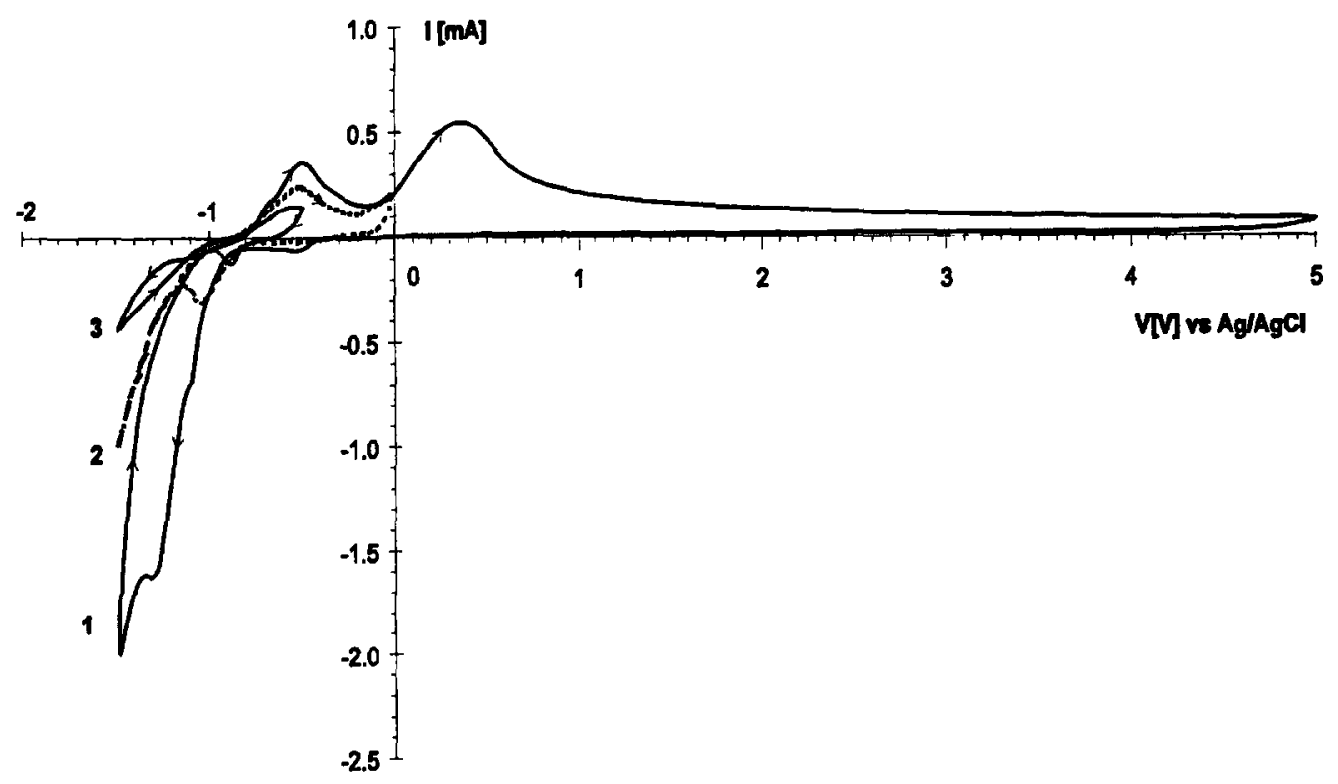

Fig. 5. Successive cyclic voltammograms of $\mathrm{Sb}$ anodized at $+5 \mathrm{~V}$ for $1 \mathrm{~h}$ showing the relation between anodic and cathodic peaks; curve $1:+5 \mathrm{~V} \Rightarrow-1.5 \mathrm{~V} \Rightarrow+5 \mathrm{~V} \Rightarrow-1.5 \mathrm{~V}$, curve $2:-1.5 \mathrm{~V} \Rightarrow 0 \mathrm{~V} \Rightarrow-1.5 \mathrm{~V}$, curve $3:-1.5 \mathrm{~V} \Rightarrow-0.5$ $\mathrm{V} \Rightarrow-1.5 \mathrm{~V}$. Same conditions.

scanned from this value to $-1.5 \mathrm{~V}$ (curve 1). The current in the greater part of the scan is very low. At $-0.5 \mathrm{~V}$ a small cathodic current plateau is observed after which the cathodic current increases strongly before levelling off. At more negative potentials (not shown) the current increases further and gas evolution is observed; hydrogen is evolved at the electrode. When the potential is scanned from $-1.5 \mathrm{~V}$ in the positive direction, the current becomes anodic, showing two peaks before returning to a value typical for oxide growth. When the potential is returned to $-1.5 \mathrm{~V}$, curve 1 is again retraced. The small cathodic current plateau (in curve 1 of Fig. 5) is absent when nitrogen is bubbled through the solution; it is very likely due to oxygen reduction. The large cathodic current peak results from the reduction of the anodic oxide. We found that the charge under the peak increases as the limit of the potential scan in the positive direction is made more positive, ie as the oxide becomes thicker. The anodic maxima in the return scan are related to nucleation and initial growth of the oxide layer [12]. The first maximum is sensitive to oxygen in the solution.

If the scan from $-1.5 \mathrm{~V}$ in the positive direction is halted at $0 \mathrm{~V}$ (curve 2, Fig. 5), the subsequent cathodic current in the reverse scan is greatly reduced. This effect is even more pronounced when

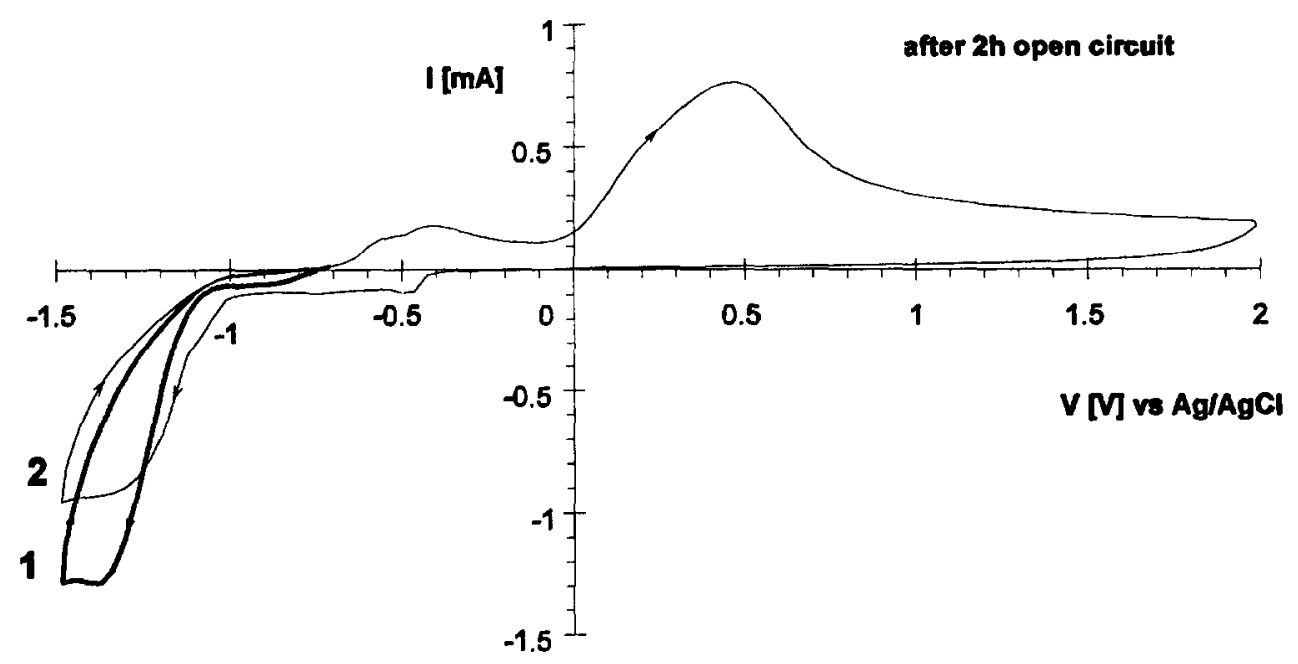

Fig. 6. Curve 1: cyclic voltammogram of $\mathrm{Sb}$ anodized at $2 \mathrm{~V}$, held for $2 \mathrm{~h}$ at open circuit potential and scanned from $-0.75 \mathrm{~V} \Rightarrow-1.5 \mathrm{~V} \Rightarrow-0.75 \mathrm{~V}$. Curve (2) is the subsequent scan from $-0.75 \mathrm{~V} \Rightarrow+2 \mathrm{~V} \Rightarrow-1.5 \mathrm{~V} \Rightarrow-0.75 \mathrm{~V}$ 
the limit of the positive scan is $-0.5 \mathrm{~V}$. Obviously to grow an oxide film with a significant thickness it is necessary to go to considerably more positive potentials.

Figure 6 gives information about the stability of the oxide film under open-circuit conditions. A $2 \mathrm{~V}$ oxide film, was held at open-circuit potential for two hours. The potential was subsequently scanned from open-circuit value (about $-0.75 \mathrm{~V}$ ) to $-1.5 \mathrm{~V}$ and back to open-circuit potential. A cathodic current (curve 1, Fig. 6) typical of oxide reduction is observed (compare with curve 1, Fig. 5). The oxide is obviously stable under open-circuit conditions (up to $24 \mathrm{~h}$ ). In order to reproduce the cathodic current-potential curve, the potential has to be scanned to $+2 \mathrm{~V}$ (curve 2, Fig. 6).

These results show that a considerable charge can be stored by forming an anodic oxide on $\mathrm{Sb}$. The oxide can be reduced cathodically; the system is reversible. The oxide seems to be quite stable in the electrolyte solution at open-circuit. These results indicate that the $\mathrm{Sb} / \mathrm{Sb}_{2} \mathrm{O}_{3}$ system may be suitable for application in the electrochemical valve. This and other oxide systems are currently being investigated.

\section{CONCLUSIONS}

The design, fabrication and operation of a new electrochemically actuated microvalve are presented. With an actuation voltage of $1.6 \mathrm{~V}$ and currents below $50 \mu \mathrm{A}$, pressures of 2 bar are easily obtained. In that case the membrane of the microvalve is deflected in the range $30-70 \mu \mathrm{m}$. The time to buildup the gas pressure is mainly determined by the charge passed through the cell, while the decrease of pressure depends on the rates of the electrochemical reactions. The performance of the actuator is determined by the efficiency of gas production; this depends not only on how gas-tight the cavity can be sealed but also on how well oxygen reduction can be suppressed.

Results obtained with the $\mathrm{Sb} / \mathrm{Sb}$-oxide electrode show that the growth of the oxide is field-dependent and that the oxide layer can be reduced electrochemically. In open circuit, the oxide is stable on a time scale of a few hours. However, further experiments are necessary to determine the long-term stability. The first results indicate that this system might be suitable as a replacement for the $\mathrm{Cu}$ electrode in the microactuator.

Advantages of the present microactuator are a low power consumption and the possibility of discontinuous energy supply. Moreover, with this system a continuous adjustment around a desired value of the membrane deflection is possible. From the present results it may be concluded that a microvalve can be actuated, using an electrochemical driving mechanism.

\section{ACKNOWLEDGEMENTS}

The authors would like to thank Erwin Berenschot for his valuable technical assistance. This research project is supported by the Netherlands Technology Foundation (STW).

\section{REFERENCES}

1. P. Gravesen, J. Branebjerg and O. S. Jensen, $J$. Micromech. Microeng. 3, 168 (1993).

2. M. Elwenspoek, T. S. J. Lammerink, R. Miyake and J. H. J. Fluitman, J. Micromech. Microeng. 4, 227 (1994).

3. R. Zengerle, W. Geiger, M. Richter, J. Ulrich, S. Kluge, A. Richter, Proc. ACTUATOR 94, p. 25 , Bremen, Germany, June 15-17 (1994).

4. P. W. Barth, Technical Digest Solid-State Sensor and Actuator Conf. (TRANSDUCERS 95), p. 276, Stockholm, Sweden, June 25-29 (1995).

5. H. Janocha, Proc. ACTUATOR 88 , p. 389 , Bremen, Germany, June 9-10 (1988).

6. W. Kempe, W. Schapper, Electrochemical actuators, Proc. Actuator 90, p. 162, Bremen, Germany, June (1990).

7. C. Neagu, J. G. E. Gardeniers, M. Elwenspoek and J. J. Kelly, J. Microelectromech. Syst. 5, 2 (1996).

8. C. Neagu, J. G. E. Gardeniers, M. Elwenspoek, J. H. J. Fluitman, Proc. ACTUATOR 96, p. 41, Bremen, Germany, June 26-28 (1996).

9. Nafion ${ }^{\mathbb{B}}$ is a E. I. du Pont de Nemours Co. Inc. registered trademark; product catalogue no. $27,470-4$.

10. T. Laitinen, H. Revitzer, G. Sundholm, J. K. Vilhunen, D. Pavlov and M. Bojinov, Electrochimica Acta 36, 2081 (1991).

11. M. Bojinov and D. Pavlov, J. Electroanal. Chem. 367, 195 (1994).

12. M. Metikoš-Hukovic, R. Babic and S. Omanovic, $J$. Electroanal. Chem . 374, 199 (1994). 